\title{
Investigation of Optimal Design for Supercooled Cloud Dispersal Equipment and Techniques ${ }^{1}$
}

\author{
WILLIAM W. VICKERS \\ Technical Operations Research Inc., Burlington, Mass. \\ AND JAmes F. Church, Major, USAF \\ Air Force Cambridge Research Laboratories, Bedford, Mass.
}

(Manuscript received 17 May 1965, in revised form 1 December 1965)

\begin{abstract}
To determine optimal cloud-seeding techniques and optimal design specifications for a dry-ice seeding machine (the Cloudbuster), multiple strip seeding of stratiform decks was performed during which seeding rate, pellet size, and strip orientation with respect to wind were systematically changed from strip to strip. Concurrently, the physical properties of the cloud decks were measured and cloud response (i.e., hole size, growth rate, etc.) to the varying treatments was measured photogrammetrically. Results showed that both the dry-ice seeding rate and peliet size, as well as the cloud temperature, exerted a strong influence on cloud response. Seeding rate had an optimum of 8 to $9 \mathrm{lb}$ per nautical mile of $\mathrm{CO}_{2}$ pellets whereafter additional quantities failed to produce consistently any increase in response. Generally, clouds failed to respond to treatment at $1.9 \mathrm{lb}$ per $\mathrm{n}$ mi. A minimum recommended quantity of $\mathrm{CO}_{2}$ pellets is $4 \mathrm{lb}$ per $\mathrm{n}$ mi using a $1 \times 1 \times 1-\mathrm{cm}$ pellet of $0.6 \mathrm{gm} \mathrm{cm}^{-3}$ density. This $\mathrm{CO}_{2}$ pellet has a fall distance of $1200 \mathrm{ft}$. When combined with other machine functions, this seeding rate and pellet size allow an output of 10,500 pellets per $\mathrm{n}$ mi. Cloud response approximately doubles between -5 and $-11 \mathrm{C}$. A response failure point exists between -3 and $-4 \mathrm{C}$. Strips should be seeded across the wind. Seeding altitude for the aircraft should be coincident with the top of the deck for all but thickest decks $(>1200 \mathrm{ft})$. For thick decks, penetration into the top one-half to one-third of the cloud decks is recommended as well as enlargement of the seeded zone by a second seeding along the perimeter of the expanding ice crystal zone.
\end{abstract}

\section{Introduction}

Although the effectiveness of dry ice on the dispersal of supercooled clouds has been adequately demonstrated, the meteorological variables that control the degree of dispersal are not known. Moreover, it is not known if there are optimum controllable conditions for seeding the clouds, such as preferred dry-ice pellet size or a preferred seeding axis with respect to the wind. The purpose of the experiments reported here was to determine the influence of the controllable technique variables, and uncontrollable meteorological variables, on cloud dispersal to enable optimal design of dry-ice dispensing equipment and seeding technique for operational aircraft use. To this end seeding experiments were flown using a dry-ice machine that was capable of varying the output of $\mathrm{CO}_{2}$ pellets, quantity of $\mathrm{CO}_{2}$, and $\mathrm{CO}_{2}$ pellet size. This machine was mounted in a C-130 aircraft.

\section{Experimental plan}

The experimental seeding missions were flown over Labrador and over the New England area during a

1 This paper is an abridgment of the following report: Vickers, W. W. and Profio, R., 1964, "Investigation of optimal design for supercooled cloud dispersal equipment and techniques," Technical Operations Research Report No. AFCRL-64-427, Air Force Cambridge Research Laboratories, $101 \mathrm{pp}$. The research was sponsored by the Air Force Cambridge Research Laboratories under Contract AF19(628)-1692, and referred to as Project Cloudbuster. three year period, 1961 through 1963. A special cloudphysics instrumented USAF C-130 aircraft belonging to the Cloud Physics Branch, Meteorology Laboratory, Air Force Cambridge Research Laboratories, was used to conduct the seeding missions and record the data. The seeding equipment consisted of a prototype (Cloudbuster) dry-ice pellet dispenser having the capability of varying its rate of pellet output, the pellet size, and pellet density. By varying either the rpm of the Cloudbuster machine or the aircraft speed, the pellet population or number of pellets per nautical mile was varied. The airborne seeding system had a total capacity of $1200 \mathrm{lb}$ of liquid $\mathrm{CO}_{2}$, which it converted into dry ice pellets with an efficiency of about 33 per cent.

The flight plan was determined by our intent to use a two-level, two-variable factorial design in which the controlled variables would be systematically varied from seeded strip to seeded strip. Restraints were imposed by the need for photogrammetric cloud response measurements and single aircraft operation. However, in general, a flight mission began with the choice of a suitable working area dictated by airways traffic and the condition of the cloud deck. The cloud deck was then sounded at a constant rate of descent $\left(500 \mathrm{ft} \mathrm{min}{ }^{-1}\right)$ and constant speed $(180 \mathrm{kt})$. Aircraft instrumentation continuously measured the cloud layer's physical properties during the descent and later ascent through the deck. The cloud deck thickness was also measured. A 


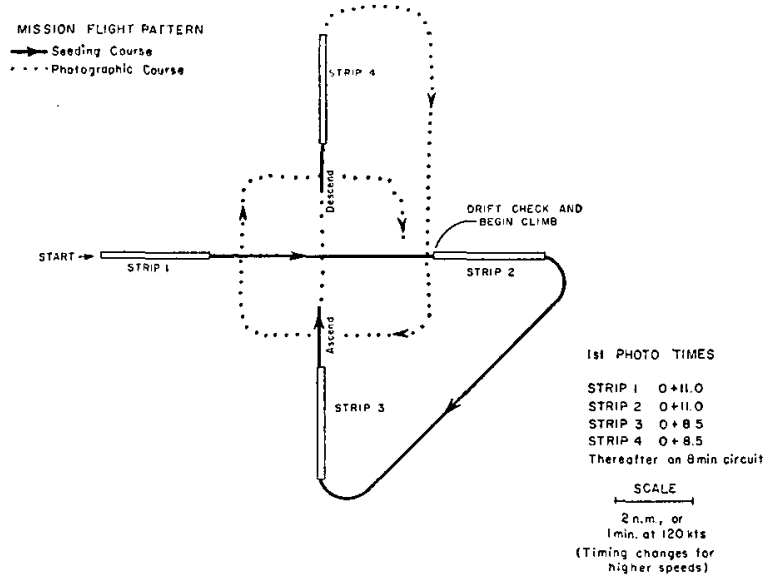

FIG. 1. Standard four-strip pattern.

heading with respect to the wind direction at cloud top height was chosen after ascending through the deck, and four strips of the cloud were seeded (Fig. 1). Strips 1 and 2 were either into the wind or across the wind at cloud top height. Strips 3 and 4 were at right angles to 1 and 2 in the manner of a plus sign, except all strips were displaced two miles from the center point. The aircraft could then fly a tight square pattern within this central displacement area so that photogrammetric measurements of cloud response could be made with the T-11 reconnaissance cameras. Under optimum conditions a seeded strip was photographed every 4 min during its life cycle after the initial 11-min delay imposed by the seeding pattern sequence.

A second seeding mission was often flown on a single deck, which added value to the data by maintaining the physical properties of the cloud deck reasonably constant. Auxiliary seeding missions to obtain certain supplemental information were also flown, such as the $\mathrm{CO}_{2}$ pellet free fall distance experiments referred to in section 5 .

\section{Variables affecting supercooled cloud dispersal}

The important cloud variables assumed likely to have a bearing on the cloud's response to treatment, as suggested by the literature or theory, were total cloud-water content, cloud-layer turbulence, cloudlayer wind shear, cloud grain, and temperature. A fifth factor, cloud droplet size, was examined and judged not likely to be important within the range encountered in fog or stratiform cloud decks. Significance of these variables is covered briefly in the following paragraphs.

Water availability, or total cloud-water content, for the growth of ice crystals is requisite to the dispersal of supercooled fog or stratus. Ice crystals must reach sufficient mass in order to precipitate from the growing clearing. On the basis of this knowledge, it has been suggested that it may be possible to overseed, i.e., there is insufficient water for the number of crystals created, and none grows sufficiently large to precipitate.
Experience indicates that there may be degrees of overseeding which are manifested in the degree of longevity of the ice-crystal cloud that invariably forms during the hole expansion stage. Braham and Sievers (cited in Vonnegut, 1946) observed that the cloud does not completely "dry up," since sufficient water remains to form clear ice on the aircraft flying through the seeded area after seeding.

Turbulence, naturally-occurring within the cloud layer or that induced by latent heat release from seeding, remains the principal mechanism for dissemination of ice seeds and water. In the present experiments, continuous accelerometer readings taken as the aircraft flew through the cloud deck were used to represent turbulence. Since comparisons to be made were relative from one cloud deck to another, an absolute vector quantity was not necessary.

Wind shear is important for the same reason that turbulence is important; it aids the dissemination of ice seeds and water vapor or liquid. True measurement of shear is difficult to make with one aircraft. Shear was approximated by examining the wind speed and general direction of the shearing action with respect to seeded strip axes, as provided by TACAN fixing of multiple aircraft positions. (Direction of shear was considered a controlled variable as the orientation of strips could be systematically varied with regard to this measurement.)

Also of interest was the cloud "grain." If a fluid is overlaid by a less dense fluid and lateral shear is applied at the interface, a wave pattern may result at the interface, with ridges and troughs that traverse the flow. The orientation of these ridges and troughs as seen in the cloud deck gives the visual effect of grain, much as the word is used to describe wood. There are also instances where grain results from horizontal helical flow which is lateral deformation of Bénard cells. Since turbulence patterns may be associated with grain, the correlation of cloud grain orientation with response of the seeded strips was investigated.

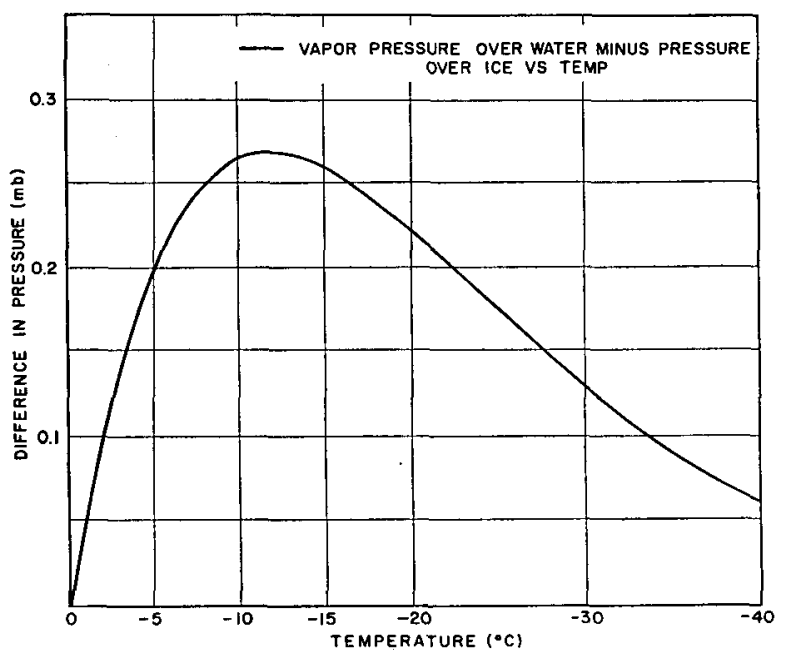

FIG. 2. Vapor pressure difference versus temperature. 
Regarding the role of temperature, the efficiency of seeding depends on the difference in the water vapor pressure over both ice and water, respectively. These vapor pressures (Smithsonian Meteorological Tables, 1951) range from a zero pressure difference at $0 \mathrm{C}$ to a maximum pressure difference at about $-12 \mathrm{C}$ back to approximately one-fifth of the maximum pressure difference at $-40 \mathrm{C}$ (Fig. 2). Because of this relation between vapor pressure difference and temperature, other things being equal, one might expect clouds near $-12 \mathrm{C}$ to show the greatest reaction to seeding.

In addition to the above cloud variables, the following controlled machine variables should be described.

Seeding rate is the weight of solid $\mathrm{CO}_{2}$ in pellet form dispensed from the aircraft per unit distance of aircraft travel. It is expressed in pounds per nautical mile. It is determined by the aircraft speed and by the delivery rate of the machine's dry-ice supply nozzle (large $=50$ lb min ${ }^{-1}$, medium $=27.5 \mathrm{lb} \mathrm{min}^{-1}$, small $=7.5 \mathrm{lb} \mathrm{min}^{-1}$ ).
The seeding rate is the supply rate divided by the aircraft speed. The significance of seeding rate is that the mass of $\mathrm{CO}_{2}$ per unit column of air is a measure of the amount of "heat sink" introduced into the volume.

The number of pellets dispensed per minute for a given supply (weight) of $\mathrm{CO}_{2}$ is fixed by the size of the pellet used and the rpm of the pelletizing wheel of the Cloudbuster machine. The rpm of the pelletizing wheel is chosen for a particular $\mathrm{CO}_{2}$ supply nozzle output and the pellet size to maintain a constant pellet density of $0.6 \mathrm{gm} \mathrm{cm}^{-3}$. Although pellet density could be varied, it was found that this density was desirable from the standpoint of smooth machine output and coherence of the pellet during its fall.

\section{Cloud response measurement terms}

The cloud texture break area is that portion of the cloud where ice seeds have formed to cause a distinct change in the appearance of the pattern of cells or rolls

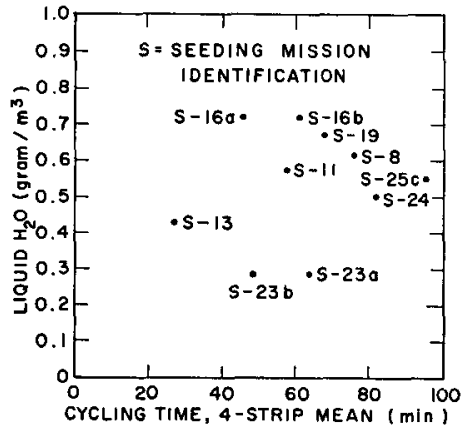

(a)

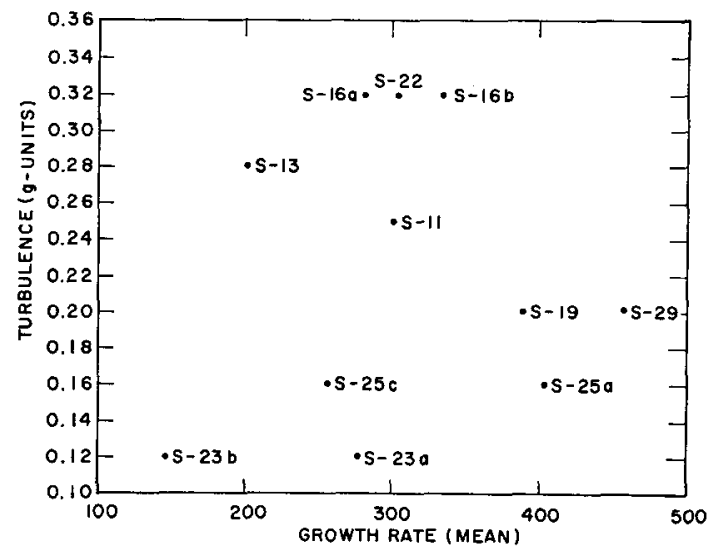

(b)

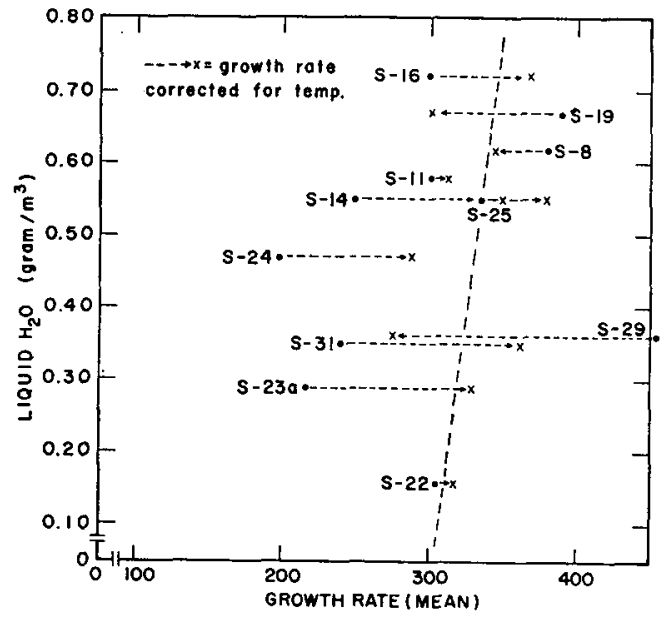

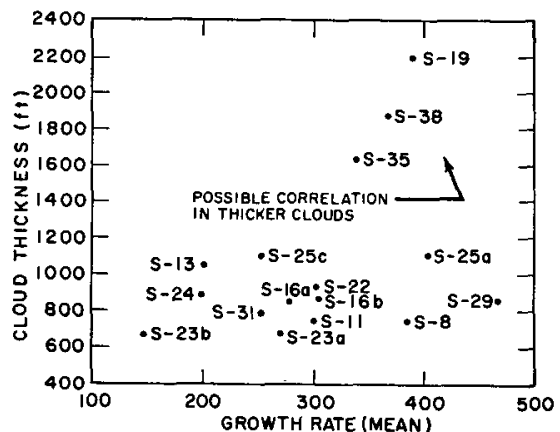

(d)

(c)

Fțc. 3. Cloud response versus physical properties. 
characterizing the upper surface of the cloud deck. The maximum width of the texture break is the distance across the affected area measured perpendicular to the seeded strip axis. The Canadian photogrammetric grid technique (Tweinkel, 1952) is used to determine both the maximum area and the maximum width of the texture break area.

The texture break, or area comprising the manufactured ice crystals, was used in the analysis of these data in preference to operational hole because it afforded more reliable measurement. The operational hole is the actual cleared section which at a minimum would allow penetration by a high-speed aircraft without its employing radical flight attitudes. The operational hole is recorded on the growth-rate curves as the percentage of cleared hole within the texture break area at various times.

The time-to-maximum width is the time required for the texture break to reach its maximum width. This value is obtained from the growth-rate curves.

The growth rate is the rate at which the texture break grows in width and is obtained from the slope of the growth-rate curve during the youthful growth stage of the seeded zone.

The cycling time is the time measured from the initial seeding to the final closing of the operational hole, often coincident with loss of texture break as well.

\section{Data treatment}

Two series of seeding flights were flown during two successive winters from which 15 standard patterns are available for complete analysis. Data on the uncontrolled variables were treated by simple correlation.

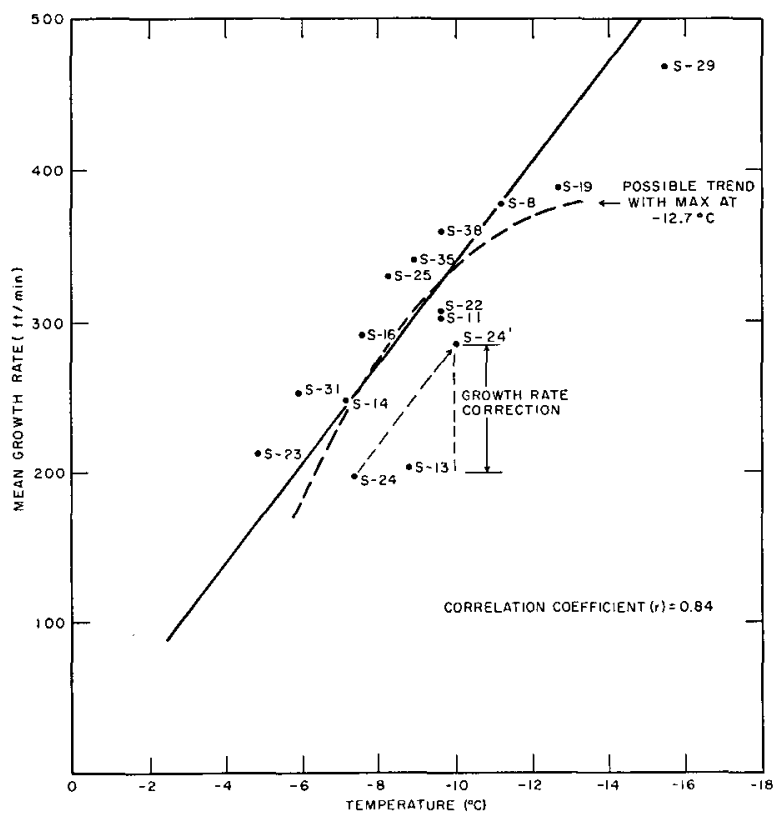

FIG. 4. Mean growth rate of four strips per mission yerșus cloud temperature.
TABLE 1. Tests showing no correlation between response and uncontrolled variables.

\begin{tabular}{lcl}
\hline Response & & \multicolumn{1}{c}{$\begin{array}{c}\text { Uncontrolled } \\
\text { variable }\end{array}$} \\
\hline $\begin{array}{c}\text { Time-to-maximum hole width } \\
\text { (for largest hole) }\end{array}$ & vs & $\begin{array}{l}\text { Liquid } \mathrm{H}_{2} \mathrm{O} \text { content } \\
\text { Cloud thickness }\end{array}$ \\
$\begin{array}{c}\text { Time-to-maximum.hole width } \\
\text { (four-strip mean) }\end{array}$ & vs & $\left\{\begin{array}{l}\text { Liquid } \mathrm{H}_{2} \mathrm{O} \text { content } \\
\text { Cloud thickness } \\
\text { Temperature }\end{array}\right.$ \\
$\begin{array}{c}\text { Maximum width of greatest break } \\
\text { Area of maximum break }\end{array}$ & vs & $\left\{\begin{array}{l}\text { Liquid } \mathrm{H}_{2} \mathrm{O} \text { content } \\
\text { Cloud thickness }\end{array}\right.$ \\
$\begin{array}{c}\text { Total area of four strips at maxi- } \\
\text { mum width }\end{array}$ & vs & $\left\{\begin{array}{l}\text { Liquid } \mathrm{H}_{2} \mathrm{O} \text { content } \\
\text { Cloud thickness } \\
\text { Turbulence in cloud }\end{array}\right.$ \\
& $\left\{\begin{array}{l}\text { Liquid } \mathrm{H}_{2} \mathrm{O} \text { content } \\
\text { Cloud thickness } \\
\text { Turbulence in cloud }\end{array}\right.$
\end{tabular}

Four-strip mean cycling time vs Cloud thickness

When factorial analysis was applied to the controlled variable data, residual errors were great enough to preclude positive identification of variable effects. The assumption of normal distributions, on which such tests are based, was apparently not justified. A switch was then made to nonparametric statistics (distribution free) for analysis of controlled variable effects (Siegel, 1956).

The principal disadvantage of nonparametric tests is that a test of ten items is only as strong (valid) as a parametric test of nine items. In effect, power efficiency is $\sim 90$ per cent. However, probability statements from most nonparametric statistical tests (small sample type, $N=6$ ) are exact probabilities, regardless of the shape of the distribution from which the sample was drawn. For a small size as small as $N=6$ (as it is in one situation here), there is no alternative to using a nonparametric statistical test unless the nature of the population is known exactly. Nonparametric statistical tests for treating samples made up of observations from several different (cloud layer) populations can handle such data without necessitating unrealistic assumptions.

Unconirolled variable effects. Scatter plots (Figs. 3 and 4) of the measured uncontrolled variables (physical properties) were made to determine the existence and degree of their influence on cloud response. Fig. 3 shows four typical plots of what appear to be random results, with the possible exception of some order existing in plot $d$, if more points had been available. Table 1 gives a list of the items tested, which produced no significant correlations. A random correlation does not necessarily mean that these variables do not have an effect in the response. They still may have some influence, but their effects are not sufficiently strong to be recognized when considered with the effects of more dominating controls like temperature (see Fig. 4). Note the strong correla- 
MISSION IDENTIFICATION REMOVED TO SIMPLIFY GRAPH

- ORIgINAL SCATTER

$X$ - TEMPERATURE CORRECTED

NUMBERS BESIDE POINTS $=A L T, k f t$

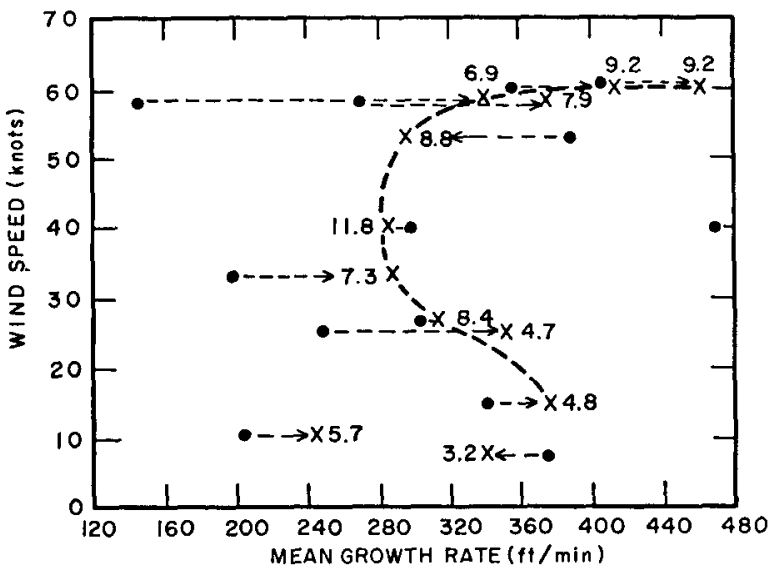

FIG. 5. Wind speed versus mean growth rate.

tion existing between cloud temperature (top third of deck) and response.

When considering the vapor pressure differential between ice and water as a function of temperature, one finds that a maximum exists at $-12.7 \mathrm{C}$ (Fig. 2). In theory, our empirical temperature-response curve (Fig. 4) should begin to reverse at temperatures below $-12.7 \mathrm{C}$. Unfortunately, insufficient points were obtained at these colder temperatures to allow verification.

Note also the effect on the liquid water content plot (Fig. 3) when it is corrected for temperature. In correcting for temperature, a plotted point is moved parallel to the temperature-response regression line (fitted by least squares) to an arbitrarily chosen standard temperature datum $(-10 \mathrm{C})$. The response value changes to that which would exist at the standard temperature. Here, since growth rate is the response considered, corrections were taken from Fig. 4. For example, if the point S-24 in Fig. 4, the mean response of four strips at $-7.2 \mathrm{C}$, is moved parallel along the regression line to position $\mathrm{S}-24^{\prime}$, determined by the position of the $-10 \mathrm{C}$ standard on the $x$ axis, the corresponding increment change of response on the $y$ axis represents the adjustment of response as a function of temperature. This response change is now applied to the response axis of the liquid water content plot of Fig. 3. In a similar manner, corrections are applied to the other data points in Fig. 3c. Note how the black dots then reduce to a slight semblance of order (pattern of $x$ 's approximating the straight dashed-line). This suggests that the scatter observed in the original liquid water content plot (black dots) was due primarily to the dominating effects of temperature. Without the temperature effect, liquid water would be indicated to have a slight effect on response.
The scatter plot of wind speed at cloud top versus growth rate response (Fig. 5) showed no correlation. However, applying temperature correction to the grow th rate produced order in the form of a hyperbolic curve that defied convincing explanation. A possible interpretation, however, can be made as follows.

The high growth rates measured at low altitudes and low wind speeds may be due to turbulence near or in the ground boundary layer, and the high growth rate at high wind speed aloft may be due to increased shear effects normally found at cloud top levels (the temperature inversion level). However, turbulence measurements at the lower levels made by the accelerometer do not support the first statement. The second statement (increased shear) might be supported by the observed presence of gravity waves (no measureable effect on accelerometer due to large scale of motion). Development of gravity waves would increase with shear, and shear would increase seed dissemination.

Thus far, we know that of all physical properties tested, cloud temperature strongly affects response, while cloud water content, turbulence, and cloud thickness have no detectable influence.

Controlled variable effects. Mission S-16 was the first to have replication of performance order (Table 2). In this instance, two missions were flown on the same

TABLE 2. Replication experiments.

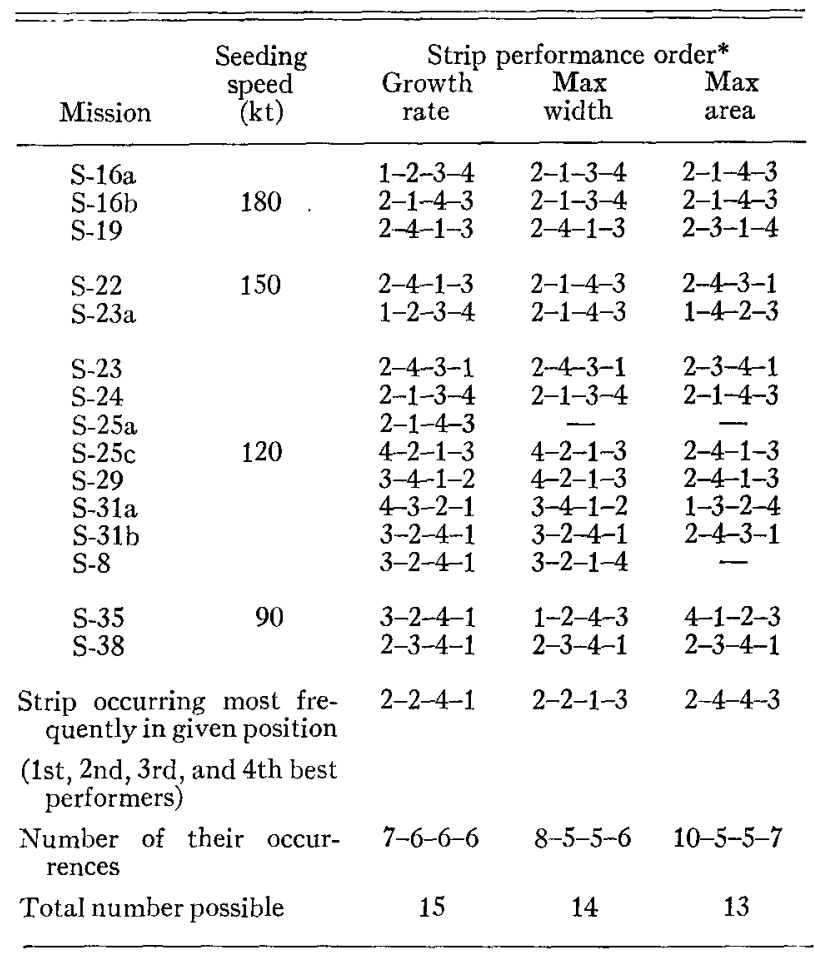

* Machine settings for any given strip are the same throughout, relative to the other respective strips:

$\begin{array}{lcccc} & 1 & 2 & 3 & 4 \\ \text { Supply nozzle size } & \text { Large } & \text { Large } & \text { Small } & \text { Small } \\ \mathrm{CO}_{2} \text { pellet size } & \text { Small } & \text { Large } & \text { Small } & \text { Large }\end{array}$


TABLE 3. Kolmogorov-Smirnov test.

\begin{tabular}{ccccc}
\hline & \multicolumn{5}{c}{$\begin{array}{c}\text { Rank of break size } \\
\text { (max area) }\end{array}$} \\
Quantity & 1 (best) & 2 & 3 & 4 \\
\hline$f$ & 10 & 0 & 3 & 0 \\
$F_{0}(X)$ & $\frac{1}{4}$ & $\frac{2}{4}$ & $\frac{3}{4}$ & $\frac{4}{4}$ \\
$S_{13}(X)$ & $\frac{10}{13}$ & $\frac{10}{13}$ & $\frac{13}{13}$ & $\frac{13}{13}$ \\
$\left|F_{0}(X)-S_{13}(X)\right|$ & $\frac{27}{52}$ & $\frac{14}{52}$ & $\frac{13}{52}$ & 0
\end{tabular}

$f=$ number of times Strip 2 occurs in the indicated position,

$F_{0}(X)=$ theoretical cumulative distribution under null hypothesis $H_{0}$,

$S_{13}(X)=$ observed cumulative distribution,

$F_{0}(X)-S_{13}(X)=$ maximum deviation, $D$,

$H_{0}=$ null hypothesis, which we define as no significant bias present, i.e., the distribution is random.

Using the maximum deviation $D$ of $27 / 52(0.52)$, the KolmogorovSmirnov test gives a probability $p$ of $<0.01$ that the distribution is random. Hence there is bias present and the null hypothesis must be rejected.

TABLE 4. Responses paired and meaned for upwind, $W_{u}$, and crosswind, $W_{c}$, seedings and for equal seeding rates.

\begin{tabular}{cccc}
\hline $\begin{array}{c}\text { Quantity } \\
\mathrm{CO}_{2} \\
\text { (lb per n mi) }\end{array}$ & $\begin{array}{c}\text { Mean growth rate } \\
\left(\mathrm{ft} \mathrm{min}^{-1}\right)\end{array}$ & $\begin{array}{c}\text { Nonparametric sign test } \\
W_{u}-W_{c}=+ \text { or }- \\
\left(\mathrm{ft} \mathrm{min}^{-1}\right)\end{array}$ \\
\hline 33.2 & 419 & 365 & $419-365=+$ \\
25.0 & 320 & 310 & $320-310=+$ \\
18.3 & 403 & 280 & $403-280=+$ \\
13.7 & 382 & 387 & $382-287=-$ \\
9.2 & 314 & 419 & $314-419=-$ \\
3.8 & 361 & 326 & $361-326=+$ \\
2.5 & 311 & 213 & $311-273=+$ \\
\hline
\end{tabular}

Number of items $\quad N=7$

Least number of like signs $r=2$

This is significant at $<25$ per cent level and the apparent upwind bias is not significant.

cloud deck repeating all settings. The resulting sequence of sizes (maximum break width, or maximum break area) for the four strips was the same for both experiments. Thereafter, the identity of the greatest and least response was as indicated in the last two columns in Table 2 for missions S-16a and S-16b.

A cursory glance at Table 2 ( $\max$ area column) shows that strip 2 gave the greatest break area in ten out of thirteen runs. In computing a quantitative measure of this intuitively obvious significance, the data will be shown to be quite different from the expectations of a random set of responses. Indeed, there is a hierarchical order.

Considering the four strips of each mission, if the ordering were completely random, one would expect all possible orders to be equally likely. Thus, one may choose any of the four strips as the best performer. Once having chosen the best strip, there are three strips left that can be chosen second best; then, two left that can be third best, and one left to be the poorest performer. The total possible number of distinguishable orders, for one mission, is thus the number of permutations of our objects, or 4 ! Since there were thirteen missions, under the hypothesis that ordering is random, there would be $(24)^{13}$ possible different outcomes. We may then revert to the basic relative frequency definition of probability and count the number of outcomes where one particular strip is best at least $n$ times. Dividing this number by the total, $(24)^{13}$, would give us the probability that a certain strip would be best $n$ times by chance. The lower the probability, the less likely the outcome would be due to chance, and consequently the more significant the evidence that there is a hierarchy involved.

Fortunately, it is not necessary for one to undergo the combinational gymnastics of counting the number of outcomes where a strip is best $n$ times. Most of these and their associated probabilities have been computed and tabulated as various statistical tests of significance. One that particularly suits our purposes is the Kolmogorov-Smirnov test. Briefly, the test involves specifying a theoretical distribution that represents what would be expected under random ordering. The point at which the two distributions, theoretical and observed, show the greatest divergence is determined. Reference to the sampling distribution indicates whether a divergence of the observed magnitude would probably occur if the observations were really a random sample from the theoretical distribution.

Table 3 gives the pertinent reduction of the information regarding the significance of strip 2 frequently having the largest area. Similar tests can be run on the other response criteria of Table 2, and for the ranks of other strips. For example, strip 3 occupies the last position less frequently than strip 2 occupies the first, but the number of occurrences is still significant $(p=<0.15)$ although not strongly so.

The reason for the decreasing predictability (note lessening of strip 2 occurrence in number 1 position toward bottom of columns in Table 2) as the field work progressed is that early seeding missions explored the low end of the seeding rate range and actually sought a failure point by using higher and higher airspeeds. Later experiments explored the saturation end of the seeding rate spectrum seeking evidence of overseeding. What will later become apparent is that the control over response exercised by seeding rate is real up to a critical point, beyond which the response appears random.

If the cloud responses to wind direction (and $\mathrm{CO}_{2}$ quantity which changed in unison with wind direction by the nature of the experimental design) were random, a given wind direction would have equal chance of producing greater response or lesser response than a competing wind direction. This is the essence of the nonparametric sign test. 
To run the nonparametric sign test, we must obtain matched pairs (in the statistical sense). These pairs are obtained by choosing two strips of each mission for which wind direction is constant, say across the seeding axis, and averaging their response values so that the effects of the accompanying small and large pellet sizes for these two strips are cancelled. A second pair is then obtained by taking the two remaining upwind strips and cancelling the pellet size effects again. Moreover, since effects of quantity cannot be meaned out, choices must also be based on a constant quantity per pair, as shown in Table 4. Since it is known from our examination of uncontrollable variables that temperature has a strong influence on response and that the other uncontrollable variables one might reasonably expect to exercise control are not significantly controlling the experiment, there is little risk in adjusting response for temperature and assuming constant conditions from day to day so that the upwind and crosswind matched pairs can be obtained. (It is tacitly assumed that no untested or undetected variable effect is present. This effect would be manifested as "chance" variation and will contribute to the imperfection of our comparison. For example, there may be a real effect due to wind structure (Fig. 5) on which we can only speculate at this juncture.)

After systematically meaning out effects due to variables not being tested, and compensating for known temperature effects, the new response values for the matched pairs are ready for comparison. It remains only to determine the statistical significance of the amount of order found in the entire collection of missions. The response used for comparison was growth rate. The results are given in Table 4 . The bias favors an upwind effect, but not strongly. This is contrary to theory (crosswind should be most favorable), and remains unexplained. Russian work (Beliaev et al., 1963) advises upwind seeding. This is apparently dictated by the geometry of the pattern recommended.

Table 4 presents upwind and crosswind response (growth rate) and the seeding rate associated with the response. Response values are those values of all

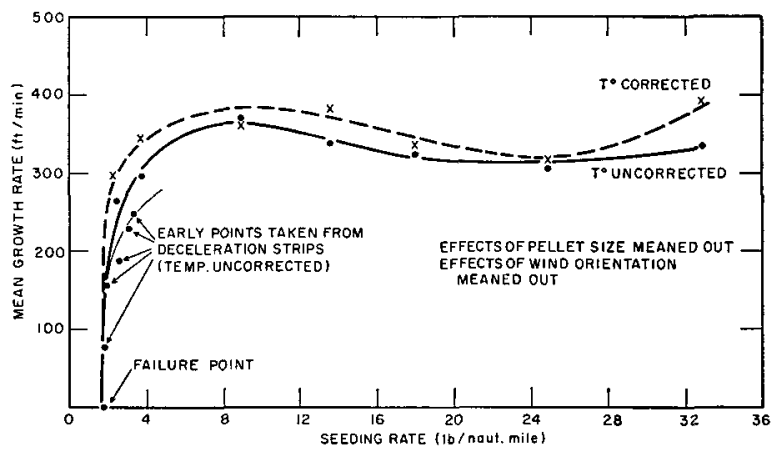

FIG. 6. Mean growth rate versus seeding rate.
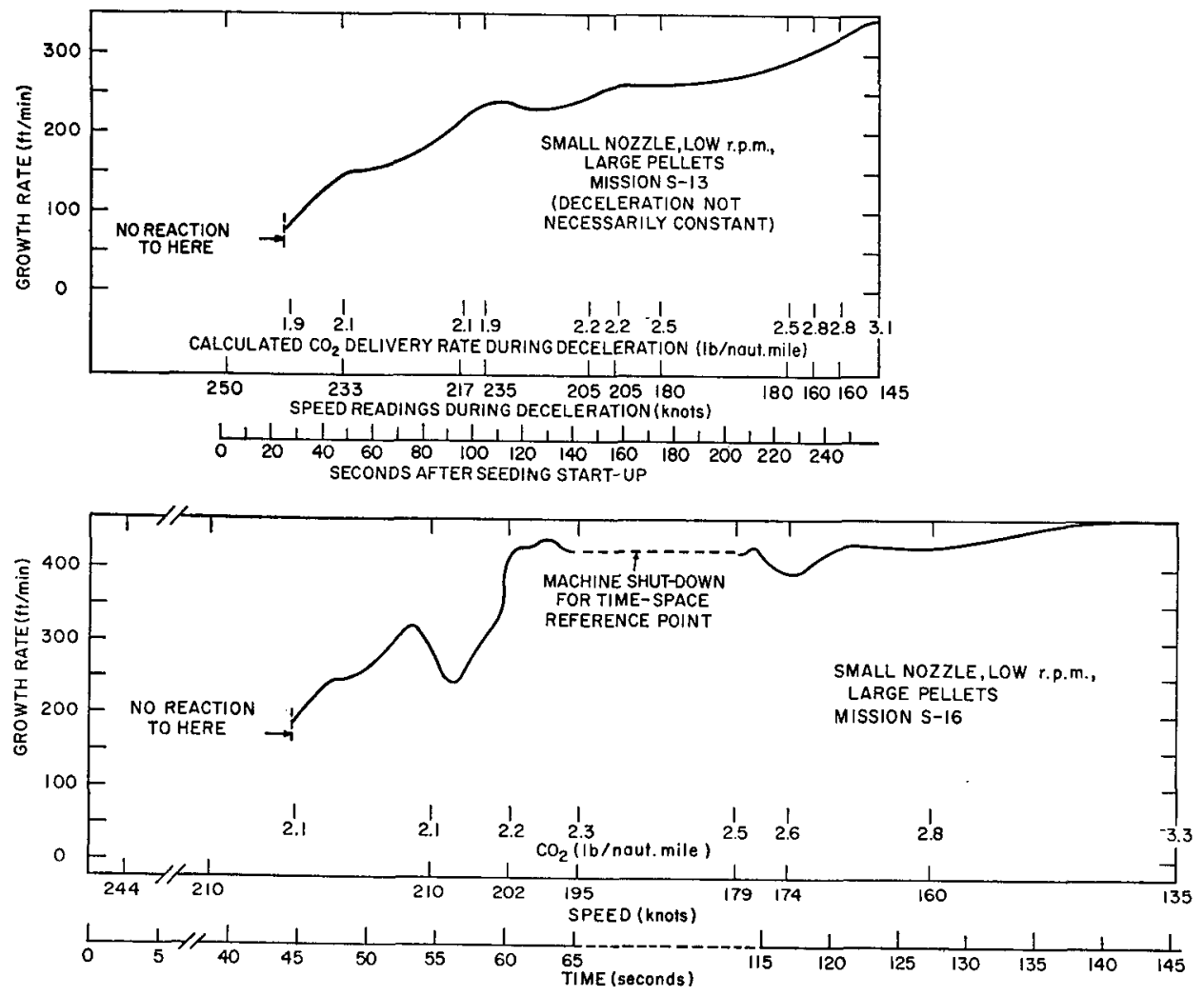

FIG. 7. Cloud response for deceleration test. 
TaBLE 5. Results, eight-strip missions.

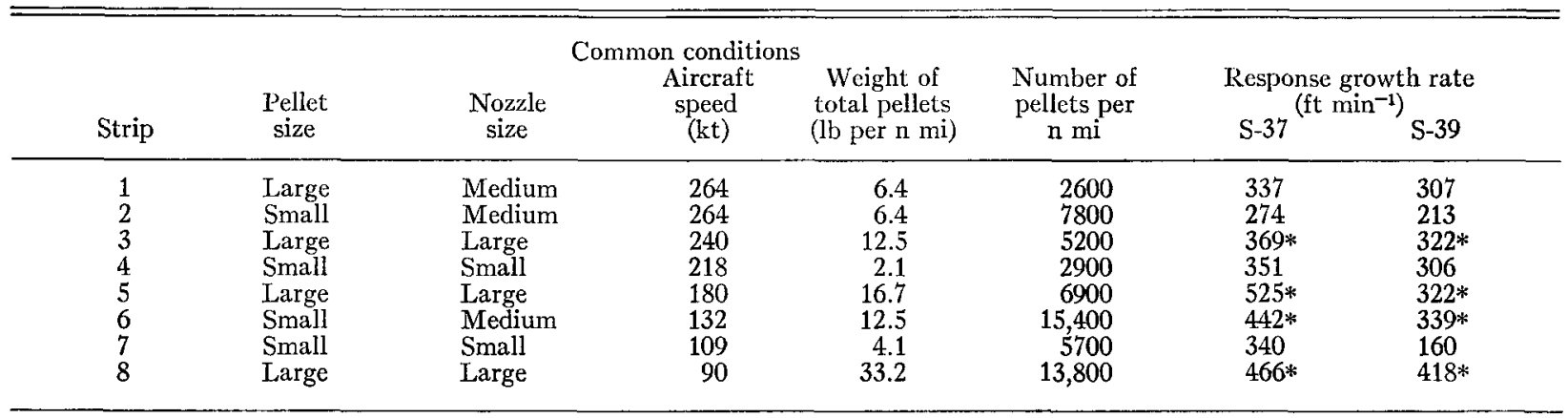

* Performing better than half of total responses, 50 percentile.

strips seeded at the particular seeding rate where effects of pellet size were meaned out, and to which temperature corrections were made. Note that an estimate of seeding rate effects can also be made by meaning the upwind and crosswind runs (cancelling any wind effects that might be present) for a given seeding amount (Table 4) and plotting meaned response vs. seeding rate as in Fig. 6. The detail at the failure end of the seeding rate spectrum for this plot was taken from the deceleration test (see following paragraph). A temperaturecorrected curve for the original data points is also plotted. The difference between the temperature-corrected and uncorrected curves merely means that the average cloud temperature during the actual missions was slightly warmer than the $-10 \mathrm{C}$ standard to which the missions were corrected. The early separation of the deceleration strip curve from the other curves also reflects temperature effects.

Tests were designed to expose the effects of seeding rate at the extreme ranges ( 1.9 to $33 \mathrm{lb}$ per $\mathrm{n} \mathrm{mi}$ ) by holding all variables constant and decelerating the aircraft from 264 to $90 \mathrm{kt}$ (Fig. 7). The curves for the two deceleration strips that are displayed provide the detail for the lower end of the seeding rate spectrum. Note the failure point at $1.9 \mathrm{lb}$ per $\mathrm{n}$ mi. This does not mean that a cloud will not react if one throws a "handful" of dry ice into it. It means that a seeding rate of $1.9 \mathrm{lb}$ of dry ice in the form of 2500 large pellets dispersed over a swath measuring $165 \times 6080 \mathrm{ft}(1 \mathrm{n} \mathrm{mi})$ will not reliably produce a hole. It also suggests that a response is a reaction or no reaction situation. If it does react, the reaction area starts with a width of approximately $2000 \mathrm{ft}$ in the form of a tapered but blunt end strip.

With increasing $\mathrm{CO}_{2}$ quantity, as shown in Fig. 6, cloud response rapidly increases until an optimum seeding rate zone is reached at 4 to $9 \mathrm{lb}$ per $\mathrm{n} \mathrm{mi}$, whereafter any further increase in seeding quantity gives no significant increase in response. In fact, there could be an overseeding point at $25 \mathrm{lb}$ per $\mathrm{n} \mathrm{mi}$, attributable to inefficient exhausting of water vapor due to too many crystals competing for available water such that they fail to develop sufficient mass to pre- cipitate. Growth rate would diminish with the inefficiency of this water vapor's exhausting mechanisms. If this is true, however, the slight increase of growth rate at $33 \mathrm{lb}$ per $\mathrm{n}$ mi becomes difficult to explain. The data are really insufficient for a confident decision on overseeding.

A given machine combination of pellet size and nozzle size will produce a certain number of pellets per minute at a certain recommended machine rpm. Some eightstrip missions were flown to provide a check on any unexpected pellet population effects (number of pellets per nautical mile) as opposed to effects of seeding rate (pounds per nautical mile) and pellet size. There remained a question of whether increasing the seeding rate was increasing response or whether increasing the rate also increased the number of pellets per unit of seeded volume and that this was the real cause of the response change. A check of this seemed possible since the large range of aircraft speed (90 to $264 \mathrm{kt}$ ) and a selection of machine settings would allow the pellet population to be varied while seeding rate was held relatively constant. Although it is immaterial whether quantity or pellet population density is responsible for the performance, the following results are cited.

Table 5 gives the results of two eight-strip missions. Replication of ranked performance was unsatisfactory. Had replication been high, the results would have been more conclusive. The large response variation in growth rates between the respective strips of S-37 and S-39 suggests that any agreement might well be random. With this qualification it is pointed out that by dividing the response into high and low values (strips $3,5,6$, and 8 are high for both missions), we see high rate (pound per nautical mile) in common. This suggests that the seeding rate is the more predominant control rather than pellet population.

Between strips 1 and 2, the rate is the same; therefore, large pellets or lower population of pellets should be the cause of the strip's goodness. However, strip 8 , a good performer, cancels this contention as pellet size, seeding rate, and population are all large.

Although seeding rate rather than pellet population appears to be responsible for the good performance, 
the data are weak and a radical change of pellet population output associated with the optimum settings indicated by the previously presented standard four-strip seeding pattern experiments is not recommended.

Fig. 8a indicates the time needed for the best performer (i.e., seeded strip) of each mission to reach maximum hole size. The mean is about $43 \mathrm{~min}$. Fig. $8 \mathrm{~b}$ indicates the meaned time elapsed to reach maximum hole size for all four strips on each seeding mission. In Fig. 8a, 32 per cent reach their maxima 31 min after seeding. When the poorer performers are included
(Fig. 8b), holes are smaller and reach their maximum widths later than the best performers.

Since the program covered so many seeding rates, there are too few data points to plot a meaningful histogram based on the narrow range of seeding rates eventually chosen as the optimum. However, such a diagram should not differ significantly from Fig. 8a.

As noted earlier, no strong correlation was found between temperature and time-to-maximum size. It appears, therefore, that a time to seed to obtain the maximum hole width cannot be based on any known

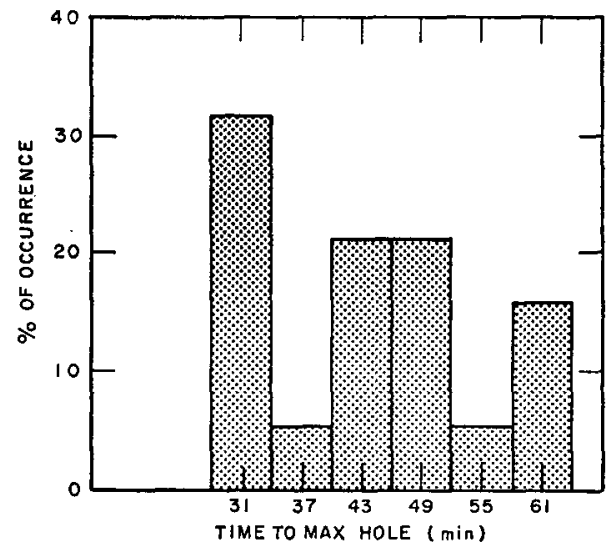

(a)

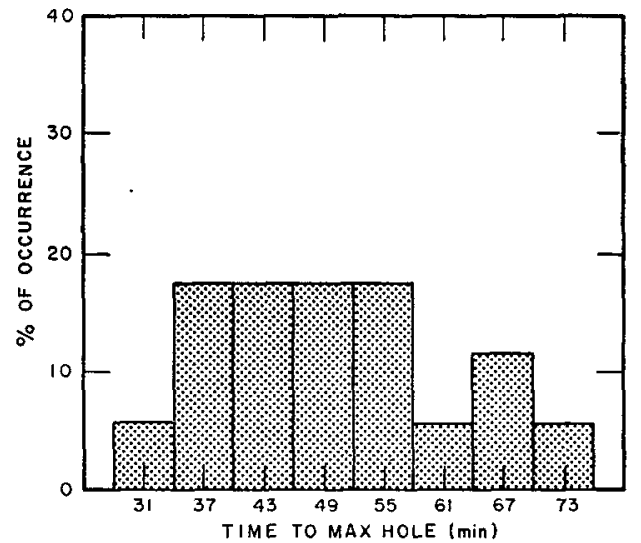

(b)

FIG. 8. Histograms showing times-to-maximum hole size.

HOLE WIDTH MEASURED AT TOP OF DECK
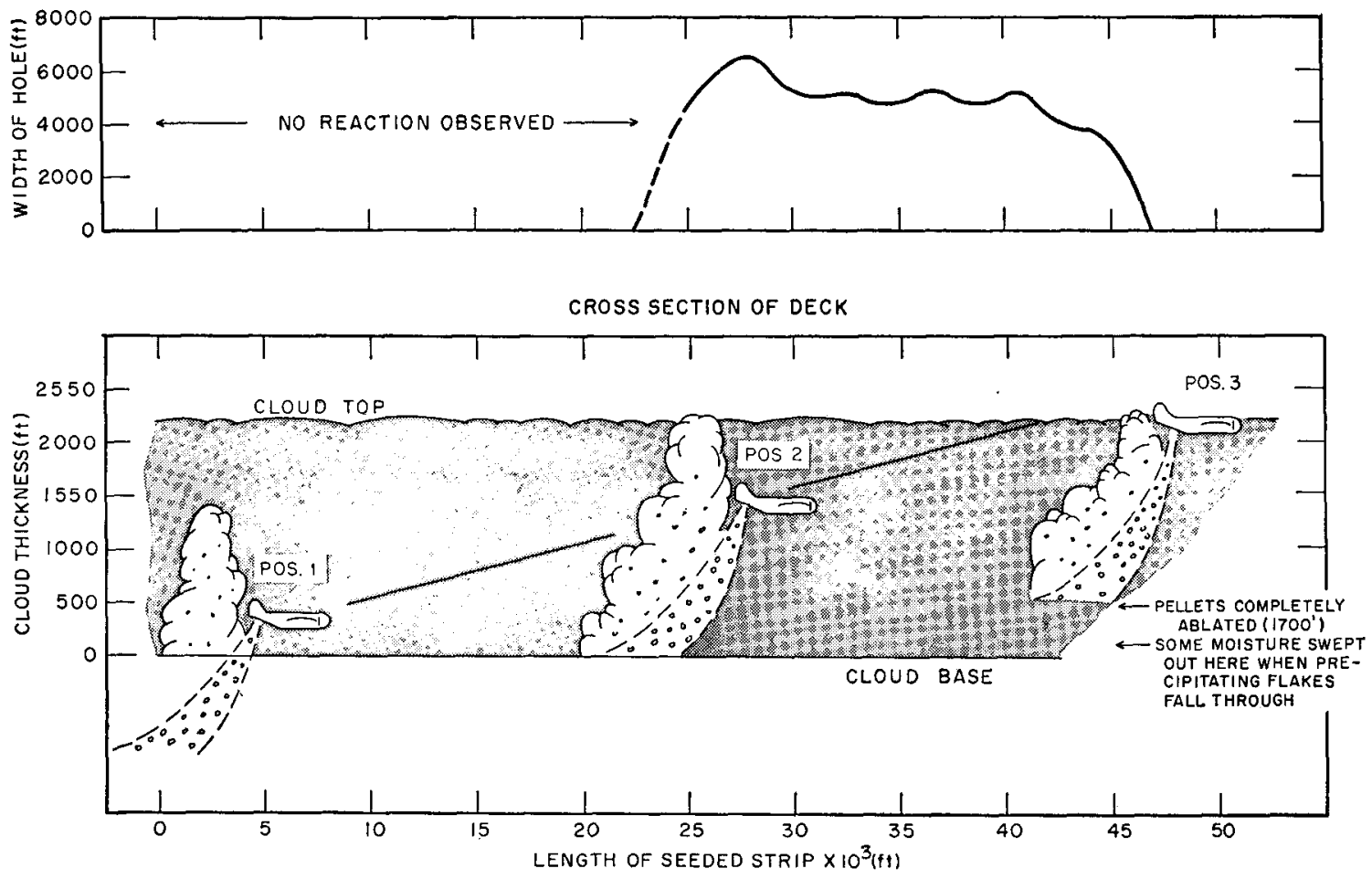

FIG. 9. Experiment indicating preferred seeding level, vertical rise of seeds, and likely maximum cloud thickness. 

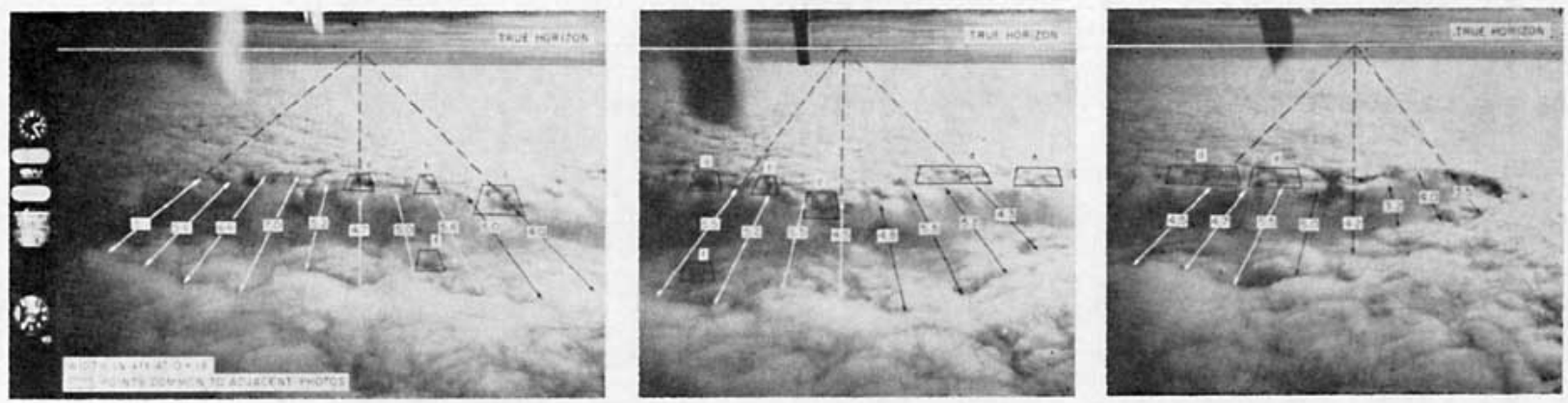

FIG. 10. Within-cloud seeding results.

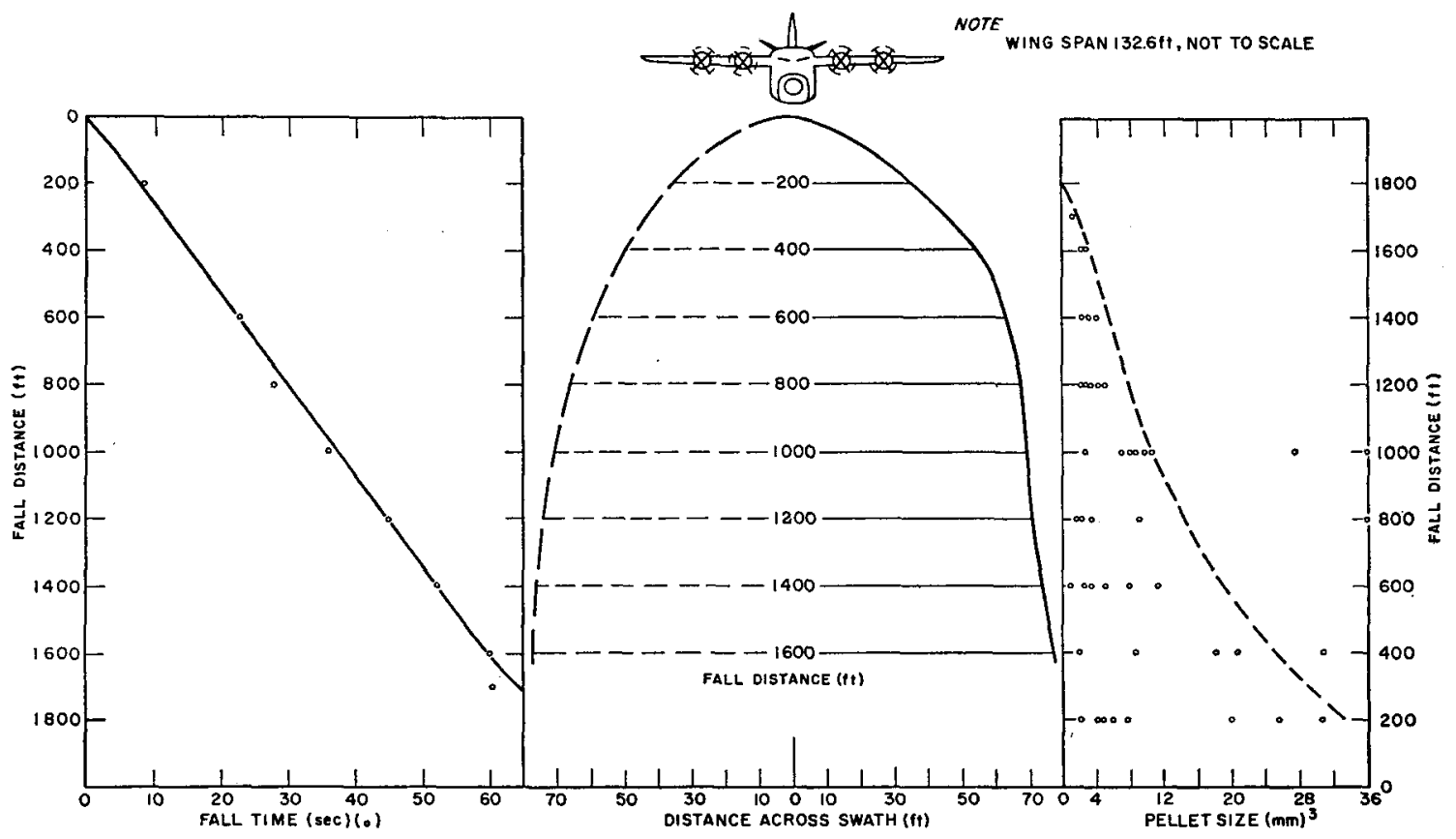

(a)

(b)

(c)

FIG. 11. Pellet drop test results.

physical influence but should be based on the mean time calculated for Fig. 8a, i.e., 43 min.

An experiment was run to test for a preferred seeding level within the cloud deck, and to see if seeding the cloud layer at its base would still open a hole by virtue of ice seeds being carried upward due to convection from the latent heat released and/or any contribution from the propeller vortices and engine exhaust heat gained.

The aircraft climbed at a constant rate through a $2200-\mathrm{ft}$ cloud deck with the dry-ice machine started at the time the aircraft entered the cloud base and stopped after the aircraft leveled off on top of the deck at which time turning off the machine was certain to give a space-time reference point for the photogrammetric analysis. The results of this seeding are shown in Figs. 9 and 10.

The ice seeds rise $1000 \mathrm{ft}$ in about $6 \mathrm{~min}$ from the cloud base level (first point of release). This estimate is derived from the observed arrival time at the upper surface, of the deck for seeds ascending through the deck from a known point of release, in this case, Position 2. (The point of release is determined by back tracking down the recorded aircraft ascent path from the spacetime reference point.) The left edge of the break above Position 2 represents either the maximum rise of the seeds; or, the point at which they gain enough mass to reverse their travel and precipitate through an upward current of $3 \mathrm{ft} \mathrm{sec}^{-1}$; or more likely, the interplay of both these phenomena.

In Fig. 9, release between approximately 1200 and $1600 \mathrm{ft}$ (Position 2) above the cloud layer base produced a modest response maximum (width). Since our experiments show that growing ice seeds will rise $1000 \mathrm{ft}$ and pellets will fall $1700 \mathrm{ft}$, it may be that the maximum response (Fig. 9, Position 2) represents the section of cloud for which the entire cloud layer received ice seeds rather than representing an optimum turbulence level. 
This suggests that $2700 \mathrm{ft}$ is the thickest cloud deck for which one can hope for success using $1 \times 1 \times 1.5-\mathrm{cm}$ pellets, with a practical limit around $1500 \mathrm{ft}$. (In mission S-35, with a deck thickness of $1630 \mathrm{ft}$, two of four holes failed to open in the operational sense.) Fortunately, 90 per cent of the supercooled stratiform decks to be encountered are less than $1500 \mathrm{ft}$ thick. It is felt from the above that producing a larger pellet capable of a greater fall distance would not necessarily open thicker decks.

To learn something of the history of the $\mathrm{CO}_{2}$ pellets after they leave the plane, the dry-ice machine was set on optimum settings ${ }^{2}$ and the aircraft made repetitive passes perpendicular to an unused runway. Each successive pass of the aircraft was $200 \mathrm{ft}$ higher in altitude. With each successive aircraft pass we measured: (1) fall time of the pellets, by stop-watch; (2) the width of the swath of pellets as they landed on the runway; (3) the population density of the pellets (pellets per square meter of runway surface within the swath); and (4) caliper size of individual pellets upon landing.

Fig. 11a shows that the maximum fall distance for the large single pellets was $1700 \mathrm{ft}$. At the end of their fall, the pellets were visually noted to have a small velocity, approximating that of a dendritic snowflake. (This was also noted in the Allied Research Associates laboratory pellet tests of fall velocity and ablation rate and was attributed to transition from turbulent to laminar flow around the falling pellet. $)^{3}$ Laboratory tests predicted a fall distance of $1800 \mathrm{ft}$. The fall timealtitude curve plots as a straight line (the solid line in Fig. 11a) that may be erroneous at the bottom since theory and our visual observations decree that it should flare slightly. Unfortunately, the observed "snowflakes" were prevented from reaching the ground by turbulent eddies, which disallowed a fall-time measurement.

The swath behind the aircraft (Fig. 11b) shows that the pellets spread to $80 \mathrm{ft}$ on either side of the aircraft centerline with the most spread occurring within the first $600 \mathrm{ft}$ of fall. The width of the pellet swath suggests that the propeller vortex is responsible for the spreading action. This could be a seeding variable that would produce a less favorable response with a single-engine aircraft.

Pellet population density was biased by the tendency of pellets to fall in clumps, thus exaggerating the count where they appeared in runway photographs. The data were therefore discarded. However, an apparent sparse pellet population density might be explained by the plot of pellet measurements (Fig. 11c) which represents the size of various pellets measured at the end of the indicated fall distance. Pellets of a particular size sublime at differing rates during their fall and those on the runway (photographically recorded) are most

\footnotetext{
${ }^{2}$ Pellet size $1 \times 1 \times 1.5 \mathrm{~cm}$, and density $0.6 \mathrm{gm} \mathrm{cm}^{3}$; seeding rate $8 \mathrm{lb}$ per $\mathrm{n} \mathbf{m i}$.

${ }^{3}$ Personal communication, Calvin Sing, A. Souza.
}

likely comparable to the larger surviving sizes. (These sizes are indicated by the dashed line in Fig. 11c.)

\section{Visible observations}

While conducting the cloud seeding experiments, several visual observation were made which warrant comment:

1) The axis of the cloud grain was observed to lie across the wind in all of the 15 experiments. Strips seeded in line with the cloud grain (across the wind) are apt to grow oval shaped, and those seeded across the grain (in line with the wind) are more apt to stay rectangular. The oval shaped strips are more likely to grow into broken or irregular patterns. From observations, it appears that flow structure of gravity waves apparently produces these differences.

2) Holes sometimes remained murky when temperatures were only slightly supercooled. This conforms to what was learned from the data analysis; namely that lower temperatures give better performance.

3) Thicker cloud decks seemed to have slower growth rates and longer cycling times for the hole to open and then close. However, this was not borne out by the data.

4) Natural influences (mesoscale turbulence patterns) exercise greater control as the holes approach maturity. This is in contrast to the predominating human control (machine controlled variables) at earlier stages of hole growth.

5) On one seeding mission where gravity waves were of 500-ft amplitude, the aircraft seeded from about $350 \mathrm{ft}$ over the trough to $150 \mathrm{ft}$ within the ridge with no significant difference in response which would be attributed to height over deck (or within deck).

6) On mission S-31 the cloud deck had large gravity waves. A strip seeded across the waves reacted only in the troughs. Since temperature conditions were marginal (about $-5 \mathrm{C}$ ), a temperature check was taken across the troughs and ridges. We reasoned that if the ridges were slightly warmer than the troughs, thus failing to react, we could closely bracket the failure point attributable to temperature. However, the ridges were $1 \mathrm{C}$ colder, $-4.8 \mathrm{C}$ in the troughs (ice crystals) versus $-5.8 \mathrm{C}$ in the ridges (water droplets). The explanation for the reaction difference must lie elsewhere, presumably in the flow dynamics.

\section{Conclusions}

Scientific. There is a strong linear correlation $(\sim 0.84)$, at least down to $-12 \mathrm{C}$, between decreasing cloud top temperature (upper one-third of deck) and the mean width of strips. Other performance criteria-growth rate, total cleared area, time-to-maximum width-also correlate with decreasing temperature. In clouds warmer than -3 and $-4 \mathrm{C}$ (true temperature, corrected for ram air heating), either the reaction to treatment will 
TABLE 6. Specificátion summary for dry-ice machine.

\begin{tabular}{|c|c|}
\hline Machine design & Specification \\
\hline $\begin{array}{l}\text { Liquid } \mathrm{CO}_{2} \text { reservoir capacity } \\
\mathrm{CO}_{2} \text { expansion-nozzle output } \\
\text { Pellet size } \\
\text { Pellet density } \\
\text { Pellet output } \\
\text { Liquid-solid } \mathrm{CO}_{2} \text { conversion efficiency }\end{array}$ & 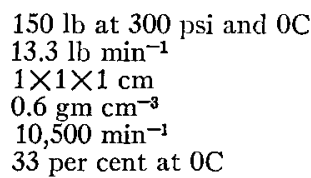 \\
\hline
\end{tabular}

Table 7. Aircraft seeding procedure.

\begin{tabular}{|c|c|}
\hline Parameter & Procedure \\
\hline Aircraft speed & 115 to $200 \mathrm{kt}$ \\
\hline Seeding direction & $\begin{array}{l}\text { Across the wind stream at cloud top } \\
\text { height }\end{array}$ \\
\hline Seeding location & $\begin{array}{l}0.73 \mathrm{hr} \times \text { wind speed }=\text { upwind distance } \\
\text { from desired cleared area }\end{array}$ \\
\hline $\begin{array}{l}\text { Seeding temperature } \\
\text { (cloud top level) }\end{array}$ & Below $-3 \mathrm{C}$ (true) \\
\hline Seeding altitude & $\begin{array}{l}\text { Cloud top level from } \leq 1200 \mathrm{ft} \text { cloud } \\
\text { thickness. Descend } 300-500 \mathrm{ft} \text { into deck } \\
\text { for } 1200-1700 \mathrm{ft} \text { thickness. Descend up } \\
\text { to } 1000 \mathrm{ft} \text { into cloud layers for decks } \\
>1700 \mathrm{ft} \text { thick }\end{array}$ \\
\hline Seeding time & $\begin{array}{l}55 \text { sec per strip at } 200 \mathrm{kt}, 115 \mathrm{sec} \text { per } \\
\text { strip at } 115 \mathrm{kt}\end{array}$ \\
\hline Separation of strips & $\begin{array}{l}1 \mathrm{n} \mathrm{mi} \text { for cloud temp. }=-3 \text { to }-9 \mathrm{C} \\
2 \mathrm{n} \mathrm{mi} \text { for cloud temp. } \leq-9 \mathrm{C}\end{array}$ \\
\hline
\end{tabular}

not occur or ice seeds will form but will return to vapor within $12 \mathrm{~min}^{4}$

Liquid water content, turbulence (within the magnitude of that found in a stratus deck), and cloud deck thickness (up to $1500 \mathrm{ft}$ ) have little or no detectable influence on cloud response. Supercooled cloud decks thicker than $1500 \mathrm{ft}$ (rare) may be difficult to clear.

Upwind seeding correlates with performance, contrary to theoretical expectation; however, the correlation is very weak, $<25$ per cent significance level. The contrariness of the upwind response and crosswind theory does not strengthen the argument for crosswind seeding, and since the crosswind effect has failed to assert itself strongly enough to be detected, we conclude there is no detectable difference between crosswind and upwind seeding.

Control of response is indeed possible by varying machine settings. Optimum seeding conditions for the equipment used are large pellets, medium nozzle, and a 205-kt aircraft speed. In quantitative terms, one wishes to produce a dry-ice pellet $1 \times 1 \times 1.5 \mathrm{~cm}$, of density $=0.6 \mathrm{gm} \mathrm{cm}^{-3}$, at a rate of 3300 pellets or $8 \mathrm{lb}$ per nautical mile. Reasonable results can be obtained by using a lesser quantity down to about $4 \mathrm{lb}$ per $\mathrm{n} \mathrm{mi}$

\footnotetext{
${ }^{4}$ Indirect communication (from Henry T. Harrison to J. F. Church, Aug. 1964); the authors have learned of instances at Medford, Oregon, where visibility has been improved a small but critical fraction of a mile in the runway approach zone at $4 \mathrm{C}$ by seeding with very heavy concentrations of dry ice $(500 \mathrm{lb})$.
}

and/or slower aircraft speeds. A failure point exists at 1.7 to $1.9 \mathrm{lb}$ per $\mathrm{n} \mathrm{mi}$, with rapid increase of response up to $4 \mathrm{lb}$ per $\mathrm{n} \mathrm{mi}$, whereafter the rate of response increase for greater quantities tapers off. A maximum exists at $8 \mathrm{lb}$ per $\mathrm{n}$ mi with a possibility of overseeding (lesser response existing at $25 \mathrm{lb}$ per $\mathrm{n} \mathrm{mi}$ ).

Pellets produced under the above recommended optimum conditions have a fall distance of $1700 \mathrm{ft}$ at $-5 \mathrm{C}$. The cone of maximum dispersal behind a C-130 aircraft is $160 \mathrm{ft}$ wide. About 88 per cent of the total lateral pellet spreading occurs within the first $600 \mathrm{ft}$ of fall.

Latent heat release and the aircraft contribution are capable of lifting seeds about $1000 \mathrm{ft}$ by convection. At this point, it is conjectured that seeds have gained sufficient mass to begin the precipitation process, thus removing themselves from the boundary contact (moisture source) of the upward expanding seeded volume. The accompanying decrease in rate of latent heat release allows the initial turbulence generated, the "boil," to stabilize. The process takes about $6 \mathrm{~min}$.

The optimum point of pellet release in thick decks $(1500$ to $2200 \mathrm{ft})$ is in the upper third of the deck. Here, the full fall distance of pellets $(1700 \mathrm{ft})$ is realized to which is added the upward convective dissemination of seeds $(1000 \mathrm{ft})$.

In very thick decks, ice crystals may be readily apparent but still do not produce a hole. This is due to the influx rate of eddy vapor transport along the sides being greater than the exhaust rate via precipitating particles. The solution should lie in increasing the size of the hole by additional seeding such that the ratio is increased of precipitating area to sidewall vapor transport area.

Operational. At the completion of this program, we recommend with confidence the specifications for an all-purpose dry-ice machine (Table 6) and simple procedures and limitations for aircraft on operational seeding missions (Table 7).

The all-purpose supercooled-cloud dissipating machine design criteria are to use $4 \mathrm{lb}$ per $\mathrm{n}$ mi of a 1 -cc volume pellet while seeding at an aircraft speed of 200 $\mathrm{kt}$. This will be a one speed, single pellet-size machine. The seeding rate can, however, be varied by changing the aircraft speed. These criteria were chosen primarily by the need to serve the high speed aircraft presently in use. Slower aircraft can still use the seeding machine, but they will seed at a higher rate. The variation in the recommended seeding rate with indicated air speed is shown in Fig. 12. For example, a slower aircraft seeding with this machine design would seed at a rate of $7.3 \mathrm{lb}$ per $\mathbf{n}$ mi at $115 \mathrm{kt}$. With a $150-1 \mathrm{~b} \mathrm{CO}_{2}$ capacity this would cut its potential total seeding distance from $12.5 \mathrm{n} \mathrm{mi}$ (for $200 \mathrm{kt}$ ) to only $7.5 \mathrm{n} \mathrm{mi}$. This is still sufficient to seed two parallel strips 3.7 miles long which would result in a minimum clearing (cloud temp -3 to $-9 \mathrm{C}$ ) of $7.5 \mathrm{n} \mathrm{mi}^{2}$ to a maximum opening (clouds colder than $-9 \mathrm{C}$ ) of about $15 \mathrm{n} \mathrm{mi}^{2}$. If the seeding was 
done at $200 \mathrm{kt}$, the minimum clearing would be about $12 \mathrm{n} \mathrm{mi}^{2}$ to a maximum of about $25 \mathrm{n} \mathrm{mi}^{2}$. Note that the above trade off allows a greater clearing capability to the faster aircraft which is more likely to need the larger clearing.

Designers of the experimental dry-ice machine used for this study strongly recommend the use of medium size pellets $(1 \times 1 \times 1 \mathrm{~cm})$ because this combination of supply nozzle, rpm, and pellet size produces a slightly better pellet and more uniform output. In the field experiments there was no response difference detected between medium and large pellets, although a response difference might have been detected if more missions had been possible. Since the difference is minor, the recommendation of the machine designers should be followed until more hardware experience is gained.

Direction and location of a seeded strip(s) should be directly upwind of the desired location by a distance equal to $40 \mathrm{~min}$ of drift. Holes will approach their maximum size by the time they drift over the airfield. Crosswind seeding is recommended since this orientation of the long axis of the hole provides a greater probability of placing some portion of the hole directly over the airfield. Parallel seeding runs for multiple strip seeding offer the optimum geometry for the mature hole.

(a)
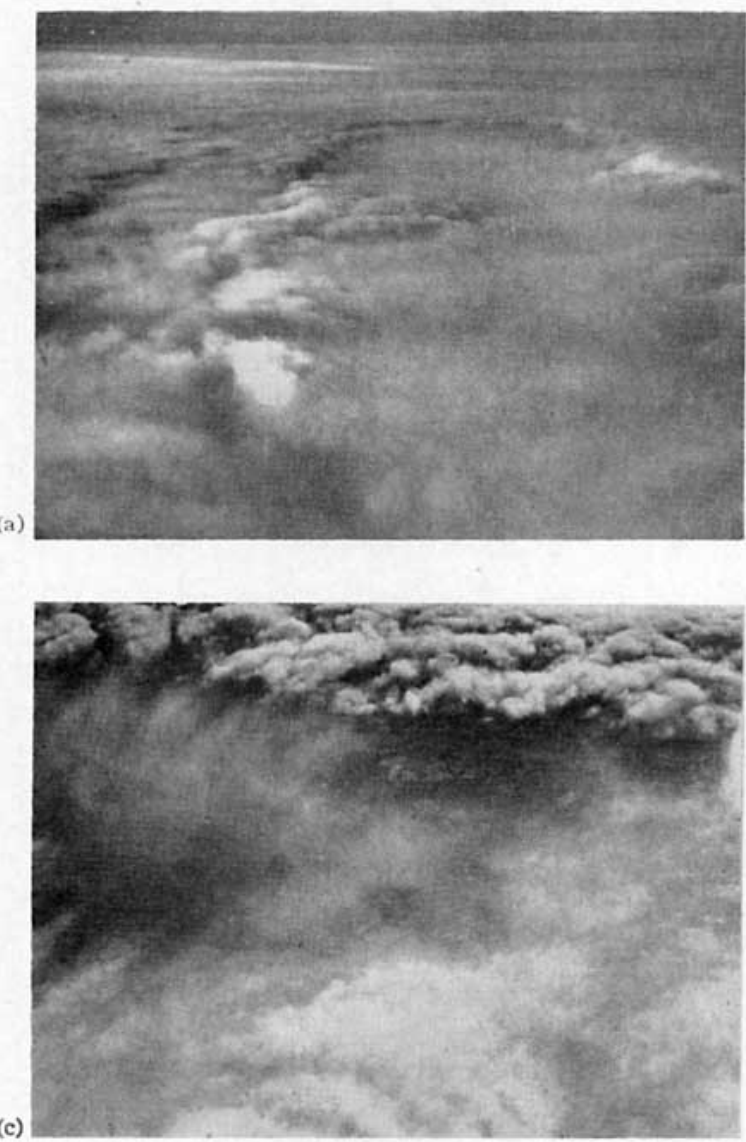

For cloud decks under $1200 \mathrm{ft}$ thick, the seeding altitude should be directly on top of the deck (pellet fall distance for medium size pellets is $1200 \mathrm{ft}$, a laboratory and field determination). For 1200 to $1700 \mathrm{ft}$ the aircraft may descend 300 to $500 \mathrm{ft}$ into the deck. For the rarely-occurring thicker decks, the seeding aircraft may descend into the deck as much as $1000 \mathrm{ft}$. For these very thick decks more experimentation is in order. For thick decks failing to open, a second seeding

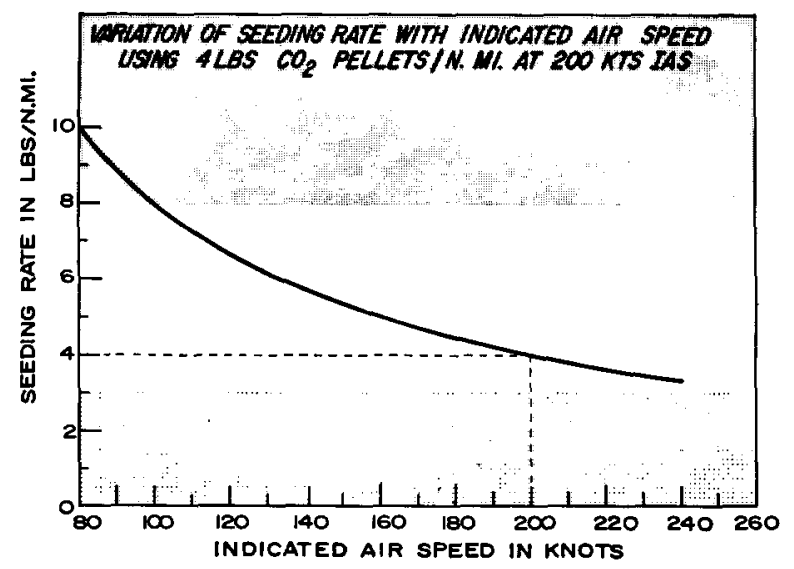

FIG. 12. Seeding rate versus air speed for constant quantity of $\mathrm{CO}_{2}$.
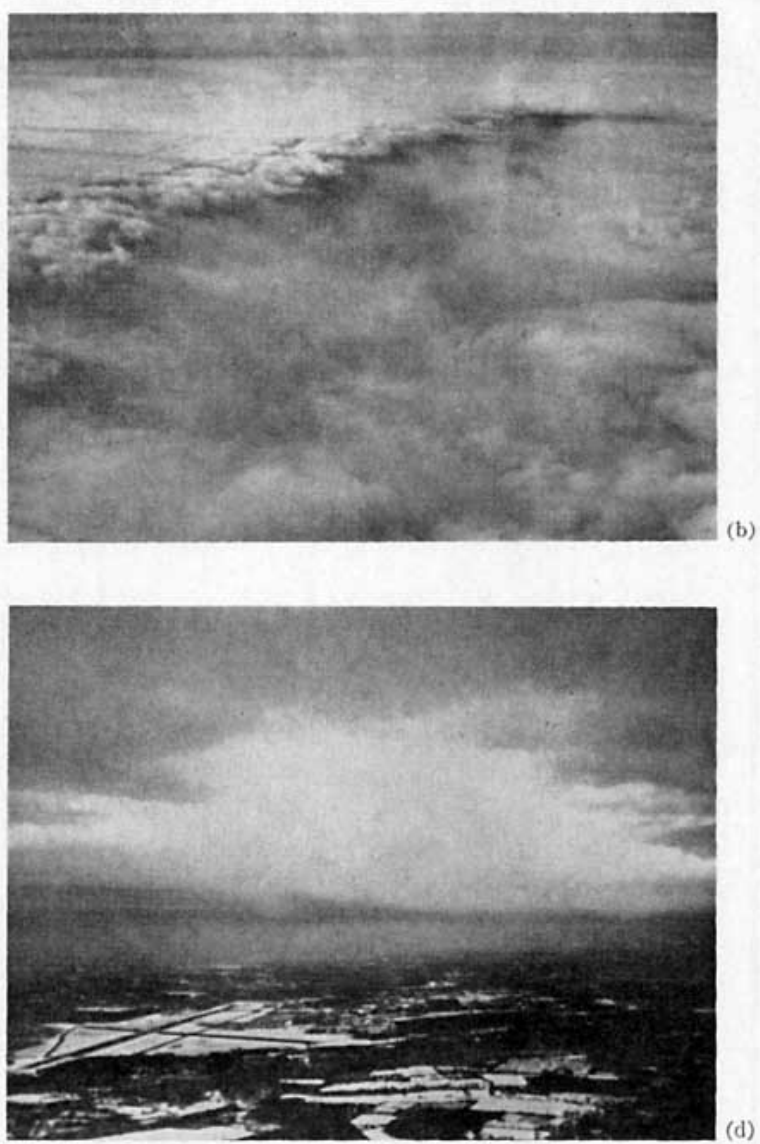

FIG. 13. Results of cloud deck seeding over L. G. Hansom Field. See text for details. 
along the edge of the observable seeded swath may help, since in theory one would wish to keep the rate of seed formation greater than the rate of turbulent diffusion effects (water importation from the surrounding deck). This latter point has not been tested since encounters with such decks were rare. (The above limits are based on the use of $1 \times 1 \times 1$-cm pellets.)

Night seeding operations can be performed satisfactorily on instruments. Virtually the entire experimental program presented herein was designed and flown around precise instrument patterns. An approximate radius of turn for aircraft type, load, and speed is the only knowledge a pilot must have for laying out parallel seeding strips. Reasonable ability to time turns and to hold heading and altitude is, of course, requisite.

In closing, one is invited to make an IFR let-down to L. G. Hanscom Field under man-made VFR conditions. Figure $13 \mathrm{a}$ shows two freshly boiling 4.5 -mile strips which have just been seeded side by side (26 min after starting first strip). In Figure 13b (47 min) the hole begins breaking at edges, and the aircraft clears for descent; Figure 13c (49 min) aircraft begins visual penetration through hole in cloud deck; Figure 13d-Hanscom Field, with overhead deck open to blue sky.

An accompanying article is being prepared for this journal to report on the design and system components of the operational version of the Cloudbuster dry-ice dispensing equipment based on the findings of this investigation.

Acknowledgments. Of great significance to the project was the C-130 flying laboratory, made available by Dr. Robert M. Cunningham of the Air Force Cambridge Research Laboratories. We wish to express our gratitude for this equipment.

We wish also to acknowledge with thanks the work of Richard Profio of Technical Operations Inc., in his successful management of a truly massive data reduction operation.

\section{REFERENCES}

Beliaev, V., I. Pavlova and V. Riabov, 1963: Methods of cloud dissipation over large areas. Akademiia Nauk SSSR, Isvestiia, Seriia Geofizicheskaia, No. 9, 1410-1416.

Siegel, S., 1956: Nonparametric Statistics, New York, McGraw-Hill Book Co., Inc., $312 \mathrm{pp}$.

Smithsonian Meteorological Tables, 1951: Washington, D. C., Smithsonian Institute.

Tweinkel, G. C., 1952: Basic mathematics of photogrammetry. Manual of Photogrammetry, 2nd ed., Washington, D. C., American Society of Photogrammetry, 355-359.

Vonnegut, B., 1946: Instruments for measuring atmospheric factors related to ice formation of airplanes. Massachusetts Institute of Technology, Department of Meteorology, Army Contract W33-038 ac-5443 (copies in MIT Lindgren and Humanities Libraries). 